\title{
Maternal Alloantigens Promote the Development of Tolerogenic Fetal Regulatory T Cells in Utero
}

\author{
Jeff E. Mold ${ }^{1,2}$, Jakob Michaëlsson ${ }^{3}$, Trevor D. Burt ${ }^{1,4}$, Marcus O. Muench ${ }^{5}$, Karen P. \\ Beckerman $6,{ }^{*}$, Michael P. Busch ${ }^{5}$, Tzong-Hae Lee ${ }^{5}$, Douglas F. Nixon ${ }^{1}$, and Joseph M. \\ McCune ${ }^{1, \dagger}$ \\ 1 Division of Experimental Medicine, Department of Medicine, University of California at San Francisco \\ (UCSF), San Francisco, CA 94110, USA \\ 2 Biomedical Sciences Graduate Program, UCSF, San Francisco, CA 94143, USA \\ 3 Center for Infectious Medicine, Department of Medicine, Karolinska University Hospital, Karolinska \\ Institutet, 141 86, Stockholm, Sweden \\ 4 Department of Pediatrics, Division of Neonatology, UCSF, San Francisco, CA 94143, USA \\ 5 Blood Systems Research Institute and Department of Laboratory Medicine, UCSF, San Francisco, CA \\ 94118, USA
}

6 Department of Obstetrics, Gynecology, and Reproductive Sciences, UCSF, San Francisco, CA 94143, USA

\begin{abstract}
As the immune system develops, $T$ cells are selected or regulated to become tolerant of self antigens and reactive against foreign antigens. In mice, the induction of such tolerance is thought to be attributable to the deletion of self-reactive cells. Here, we show that the human fetal immune system takes advantage of an additional mechanism: the generation of regulatory $T$ cells $\left(T_{\text {regs }}\right)$ that suppress fetal immune responses. We find that substantial numbers of maternal cells cross the placenta to reside in fetal lymph nodes, inducing the development of $\mathrm{CD} 4+\mathrm{CD} 25^{\text {high }} \mathrm{FoxP} 3+\mathrm{T}_{\text {regs }}$ that suppress fetal antimaternal immunity and persist at least until early adulthood. These findings reveal a form of antigen-specific tolerance in humans, induced in utero and probably active in regulating immune responses after birth.
\end{abstract}

Fifty years ago, Billingham, Brent, and Medawar first advanced the concept that "actively acquired immunologic tolerance" in the mouse occurs as a result of fetal exposure to foreign antigens (1). There have since been numerous reports suggesting that the transfer of foreign antigens (including proteins, parasites, and even cells) from the mother to the fetus is a common occurrence (2-4); however, the mechanism by which the fetal immune system recognizes and responds to such antigens is unclear.

Temporal differences in the development of the adaptive immune system vary substantially between species (5). Newborn mice show few signs of peripheral T cell colonization (6), whereas in the human fetus, peripheral lymphoid tissues are populated by $\mathrm{T}$ cells as early as 10 gestational weeks (g.w.) (7). Therefore, it is not clear whether in utero tolerance induction would occur upon fetal exposure to foreign antigens in the human as it does in the mouse (8). In fact, not much is known about the functional properties of the human fetal immune system:

†To whom correspondence should be addressed. E-mail: mike.mccune@ucsf.edu.

Present address: Albert Einstein College of Medicine, Bronx, NY 10461, USA. 
Some reports suggest that it is functionally deficient, whereas others indicate that fetal immune responses to pathogens and vaccines are intact (9-12). In two independent clinical studies $(13,14)$, specific tolerance toward noninherited maternal alloantigens (NIMAs) was observed in organ transplant recipients, consistent with the possibility that fetal exposure to NIMAs may promote lasting tolerance in humans.

In certain circumstances [for example, severe combined immunodeficiency disease (15)], maternal cells cross the placenta and engraft into human fetal tissues in utero, resulting in "maternal microchimerism" (4). Because the human fetal immune system may be functionally responsive against NIMAs in utero, we wished to understand whether such microchimerism was the exception or the norm. Lymph nodes (LNs) were isolated from the mesentery of 18 fetal products of conception at 18 to 22 g.w. and analyzed for the presence of maternal DNA (16). Maternal microchimerism was observed in 15 out of $18 \mathrm{LN}$ samples (Table 1 and fig. S1), with a frequency ( 0.0035 to $0.83 \%$ ) comparable to that reported in nonlymphoid organs from human fetal specimens, neonates, and healthy adults $(17,18)$. Our analysis of the cellular composition of maternal cells in neonatal cord blood revealed a predominance of hematopoietic cells (fig. S2). To determine whether human fetal $\mathrm{T}$ cells are responsive against foreign human leukocyte antigens (HLAs) (alloantigens), fetal ( 20 g.w.) lymphocytes from the spleen or LNs (Fig. 1A and fig. S3) were labeled with the dye carboxy-fluorescein diacetate succinimidyl ester and cocultured with irradiated antigen-presenting cells (APCs) from the peripheral blood of a single healthy, unrelated adult donor (19). After 5 days in this mixed leukocyte reaction (MLR), substantial proliferative responses were observed for both CD4+ and CD8+ fetal T cells (Fig. 1A), prompting the following question: If fetal $\mathrm{T}$ cells respond so vigorously against alloantigens in vitro, would they not also respond against NIMAs expressed by maternal cells that have moved into fetal LNs in utero?

We recently reported that, compared to adults, elevated frequencies of regulatory $\mathrm{T}$ cells $\left(\mathrm{T}_{\text {regs }}\right.$ ) are found in human secondary fetal lymphoid tissues (20). Because $\mathrm{T}_{\text {regs }}$ are known to regulate maternal immunity to fetal alloantigens (21), we reasoned that fetal $\mathrm{T}_{\text {regs }}$ may suppress fetal immune responses against invading maternal cells. Depletion of $\mathrm{T}_{\text {regs }}(\mathrm{CD} 25+\mathrm{T}$ cells) resulted in a highly significant increase in proliferation of fetal $\mathrm{T}$ cells against maternal APCs but only a slight increase against unrelated APCs (Fig. 1, B to D). We also noted an increase in proliferation when autologous APCs were used as stimulators, suggesting that $\mathrm{T}$ cell responses to self antigens are suppressed by fetal $\mathrm{T}_{\text {regs. }}$. These data indicate that fetal Tcells are not inherently deficient at responding to maternal alloantigens; rather, their function is actively suppressed by a large pool of fetal $\mathrm{T}_{\text {regs }}$.

Natural $\mathrm{T}_{\text {regs }}$ originate in the thymus and are specific for self antigens presented by thymic epithelial cells (22). We found no difference in the frequency of CD4+FoxP3+ $\mathrm{T}_{\text {regs }}$ between the fetal and infant thymus (fig. S4). In contrast, the frequency of $\mathrm{T}_{\text {regs }}$ in peripheral lymphoid organs changes markedly during the course of gestation, falling from $\sim 15$ to $20 \%$ of total CD4 $+\mathrm{T}$ cells at 12 to 20 g.w. to $\sim 3$ to $7 \%$ at birth (23). We reasoned that this change in frequency might reflect a greater propensity of naïve fetal $\mathrm{T}$ cells to differentiate into $\mathrm{T}_{\text {regs }}$ in response to stimulation. To test this, we depleted fetal LNs (and spleen) (fig. S5A) of CD25+ $\mathrm{T}_{\text {regs }}$ and stimulated the remaining cells with irradiated APCs from an unrelated donor. After a 5-day culture period, many of the dividing fetal $\mathrm{T}$ cells had up-regulated the transcription factor FoxP3, which is directly involved in promoting $\mathrm{T}_{\text {regs }}$ development and function (24) (Fig. 2A). To further characterize the kinetics of this response, we performed a parallel analysis of FoxP3 up-regulation after stimulation of fetal or adult $\mathrm{T}$ cells (depleted of $\mathrm{T}_{\text {regs }}$ ) with a single unrelated donor (Fig. 2B and figs. S5 and S6). Whereas both fetal and adult T cells displayed similar patterns of activation during the first 2 days of stimulation (figs. S5 and S6), fetal T cells showed greater signs of activation thereafter (Fig. 2B and figs. S5 and S6). Sustained expression of FoxP3 is a necessary feature of $\mathrm{T}_{\text {regs }}$ in both mice and humans. Whereas adult $\mathrm{T}$ cells can 
express FoxP3 after stimulation (22), we found that most activated adult T cells were CD25 +FoxP3 - after 6 days of stimulation. Expression of FoxP3 by fetal Tcells was maintained over the course of the stimulation period, with $\sim 50 \%$ of fetal CD4+ T cells expressing both CD25 and FoxP3 by day 6 (Fig. 2B).

Environmental cues play a central role in determining $\mathrm{T}$ cell differentiation pathways during an immune response. To address whether fetal lymphoid tissues are enriched for cytokines that might favor $\mathrm{T}_{\text {regs }}$ differentiation during $\mathrm{T}$ cell activation, cytokine gene expression patterns were evaluated in fetal $(n=5)$ and adult ( $n=4)$ LNs (Fig. 2C). As anticipated, adult LNs had elevated levels of interleukins and interferons as compared with fetal LNs. Analysis of tumor necrosis factor (TNF) family members revealed more variable expression patterns, with transcripts for some genes (e.g., OX40L, CD70, and APRIL) being higher in adult LNs, whereas others (e.g., LT $\alpha$, LT $\beta$, TRANCE) were more highly expressed in fetal LNs. TNF family members more highly expressed by fetal LNs were predominantly those important for LN organogenesis in mice (e.g., LT $\alpha, \mathrm{LT} \beta$, TRANCE, and TNF $\alpha$ ) (25). Many transforming growth factor- $\beta$ (TGF $\beta$ ) family members were more highly expressed in fetal LNs, including bone morphogenic proteins 1 to 5,7 , and $8 \mathrm{~B}$; growth and differentiation factors $2,3,10$, and 11 ; as well as TGF $\alpha$ and TGF $\beta$ s. High expression of various TGF $\beta$ family members in developing LNs is consistent with the role that members of this family play in embryonic developmental pathways (26). TGF $\beta$ signaling is known to induce FoxP3 up-regulation during $\mathrm{T}$ cell activation and to be critical for the differentiation of $\mathrm{T}_{\text {regs }}$ during an immune response. To test whether TGF $\beta$ signaling was required for FoxP3 up-regulation during fetal Tcell responses, we measured FoxP3 expression in a 5-day MLR in the presence or absence of a TGF $\beta$ inhibitor (SB 431542) and found that inhibition of TGF $\beta$ signaling resulted in a large reduction in FoxP3 up-regulation by fetal T cells (Fig. 2D).

Because FoxP3 can be induced in some activated $\mathrm{T}$ cells that are not functionally suppressive (22), we determined whether FoxP3 expression after fetal $\mathrm{T}$ cell activation was associated with the acquisition of suppressive function. Primary MLRs were performed with fetal CD25depleted LN cells, with or without TGF $\beta$ inhibition; endogenous splenic $\mathrm{T}_{\text {regs }}$ served as a positive control. After a 7-day culture period, fetal CD25-depleted LN cells and splenic $\mathrm{T}_{\text {regs }}$ were tested for function in a conventional add-back assay. Fetal LN cells that had up-regulated FoxP3 after stimulation with adult allogeneic APCs were functionally suppressive, whereas those activated in the presence of the TGF $\beta$ inhibitor lacked the ability to suppress T cell proliferation (Fig. 2E and fig. S7). Although the endogenous pool of fetal splenic $\mathrm{T}_{\text {regs }}$ appeared to have increased suppressive function (Fig. 2E), this may reflect a greater percentage of FoxP3 + cells within this population: $\sim 30$ to $50 \%$ of CD4+ T cells from fetal LNs had up-regulated FoxP $3+$ after 7 days of stimulation in vitro, whereas $\sim 50$ to $80 \%$ of splenic endogenous $\mathrm{T}_{\text {regs }}$ were FoxP3+ after 7 days in culture (fig. S7B).

The above studies indicate that suppressive $\mathrm{T}_{\text {regs }}$ are generated against NIMAs in utero. Given previous reports indicating that NIMAs are better tolerated than non-inherited paternal alloantigens in the setting of adult solid organ transplantation $(13,14)$, we tested the possibility that $\mathrm{T}_{\text {regs }}$ generated against NIMAs in utero might persist after birth. We performed MLRs using lymphocytes of children (ages 7 to 17 years old) to measure $\mathrm{T}$ cell proliferation in response to maternal or paternal alloantigens, with or without prior depletion of $\mathrm{T}_{\text {regs }}$ (Fig. 3, A to $\mathrm{C}$ ). Some children demonstrated $\mathrm{T}_{\text {regs }}$ suppression against maternal alloantigens but not against paternal alloantigens (Fig. 3, B and C) or autologous APCs (fig. S8). A parallel analysis of maternal and paternal Tcell responses directed against their children's alloantigens revealed that maternal $\mathrm{T}_{\text {regs }}$ with specificity for their children's alloantigens persist long after birth as well (fig. S8H). These preliminary findings indicate that $\mathrm{T}$ cell tolerance to alloantigens perceived in utero may, in some cases, be maintained after birth through the establishment of long-lived $\mathrm{T}_{\text {regs }}$, as has been reported for B cell tolerance (13). 
It has long been recognized that central deletion of autoreactive $\mathrm{T}$ cell clones is an important mechanism for generating immunological tolerance. Here, we demonstrate that the fetal peripheral adaptive immune system can rapidly generate functionally suppressive $T_{\text {regs }}$, providing another mechanism by which the fetus can establish tolerance to foreign and self antigen present during development in utero. Although this study has focused on fetal tolerance to maternal alloantigens, there is no reason to believe a priori that the fetal immune system would respond differently to other antigens encountered in utero, including self antigens, food antigens, and antigens associated with infectious agents carried by the mother. Further investigation into these areas is likely to provide important insights about the treatment of fetal disease, the development of tolerance to self and foreign antigens in humans, the establishment of strategies to induce antigen-specific tolerance during fetal development, and the pathogenesis of mother-to-child transmission of pathogens, such as HIV, in utero.

\section{Supplementary Material}

Refer to Web version on PubMed Central for supplementary material.

\section{References and Notes}

1. Billingham RE, Brent L, Medawar PB. Nature 1953;172:603. [PubMed: 13099277]

2. Gitlin D, Kumate J, Urrusti J, Morales C. J Clin Invest 1964;43:1938. [PubMed: 14236218]

3. Remington, JS.; Klein, JO.; Wilson, CB.; Baker, Carol J. Infectious Diseases of the Fetus and Newborn Infant. Vol. 6. Elsevier Saunders; Philadelphia, PA: 2006. p. 11-16.

4. Adams KM, Nelson JL. JAMA 2004;291:1127. [PubMed: 14996783]

5. Silverstein AM. Science 1964;144:1423. [PubMed: 14171536]

6. Friedberg SH, Weissman IL. J Immunol 1974;113:1477. [PubMed: 4608249]

7. Haynes BF, Heinly CS. J Exp Med 1995;181:1445. [PubMed: 7699329]

8. West LJ. Hum Exp Toxicol 2002;21:499. [PubMed: 12458907]

9. Rayfield LS, Brent L, Rodeck CH. Clin Exp Immunol 1980;42:561. [PubMed: 6452236]

10. Granberg C, Hirvonen T. Cell Immunol 1980;51:13. [PubMed: 6444846]

11. Marchant A, et al. J Clin Invest 2003;111:1747. [PubMed: 12782677]

12. Rastogi D, et al. J Clin Invest 2007;117:1637. [PubMed: 17549258]

13. Claas FH, Gijbels Y, van der Velden-de Munck J, van Rood JJ. Science 1988;241:1815. [PubMed: 3051377]

14. Burlingham WJ, et al. N Engl J Med 1998;339:1657. [PubMed: 9834302]

15. Muller SM, et al. Blood 2001;98:1847. [PubMed: 11535520]

16. Lee TH, et al. Transfusion 2006;46:1870. [PubMed: 17076840]

17. Jonsson AM, Uzunel M, Götherström C, Papadogiannakis N, Westgren M. Am J Obstet Gynecol 2008;198:325.e1. [PubMed: 18191801]

18. Loubière LS, et al. Lab Invest 2006;86:1185. [PubMed: 16969370]

19. Materials and methods are available as supporting material on Science Online.

20. Michaëlsson J, Mold JE, McCune JM, Nixon DF. J Immunol 2006;176:5741. [PubMed: 16670279]

21. Aluvihare VR, Kallikourdis M, Betz AG. Nat Immunol 2004;5:266. [PubMed: 14758358]

22. Vignali DAA, Collison LW, Workman CJ. Nat Rev Immunol 2008;8:523. [PubMed: 18566595]

23. Takahata Y, et al. Exp Hematol 2004;32:622. [PubMed: 15246158]

24. Hori S, Nomura T, Sakaguchi S. Science 2003;299:1057.10.1126/science.1079490 [PubMed: 12522256]published online 9 January 2003

25. Mebius RE. Nat Rev Immunol 2003;3:292. [PubMed: 12669020]

26. Kitisin K, et al. Sci STKE 2007 2007:cm1.

27. We would like to thank the families who donated blood for the studies shown in Fig. 3. We also thank B. Kanwar, D. Favre, E. Trachtenberg, R. Derynck, and S. Fisher for technical assistance and valuable 
discussions. Support for this work was provided by grants from NIH to J.M.M (OD000329 and AI40312) and D.F.N. (AI68498) and from the AIDS Biology Program of the AIDS Research Institute at UCSF. J.M. is supported by the Swedish Research Council. T.D.B. is a National Institute of Child Health and Development fellow (HD00850) and was also funded by the American Academy of Pediatrics and the American Pediatric Society. M.O.M. was supported by grants from the Broad Medical Research Program of The Eli and Edythe L. Broad Foundation, National Blood Foundation, and Blood Systems, Inc. K.P.B. was supported by grants from the UCSF Clinical and Translational Institute Clinical Research Center (RR024131) and the Elizabeth Glaser Pediatric AIDS Foundation (PG-50804). M.P.B. and T.-H.L. were both supported by grants from the National Heart Lung and Blood Institute (HL083388). J.M.M. is a recipient of the NIH Director's Pioneer Award Program. 
A
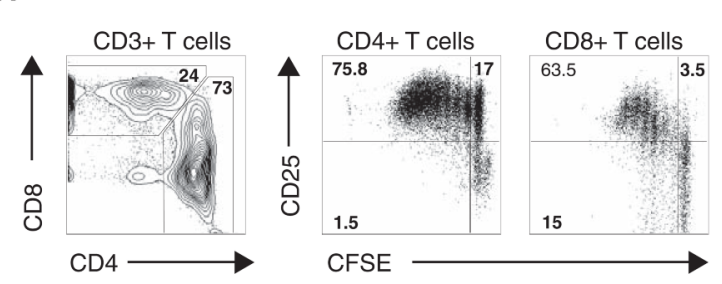

B
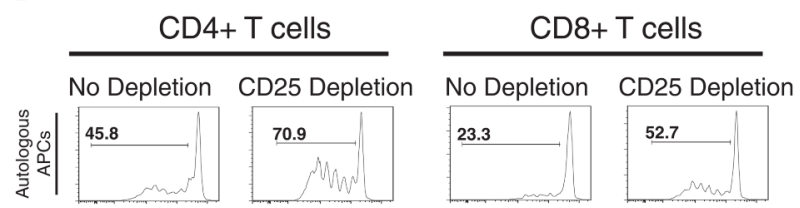

23.3
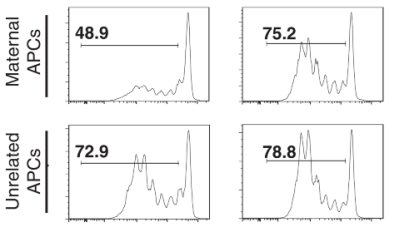

C
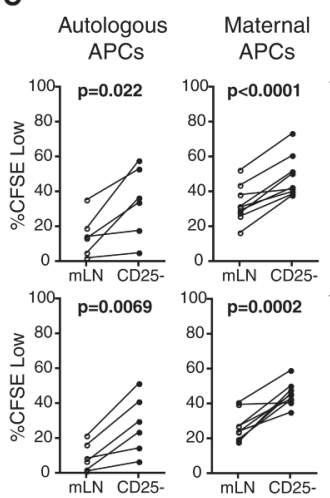

Unrelated
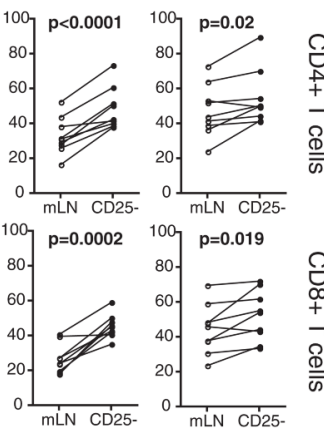

D
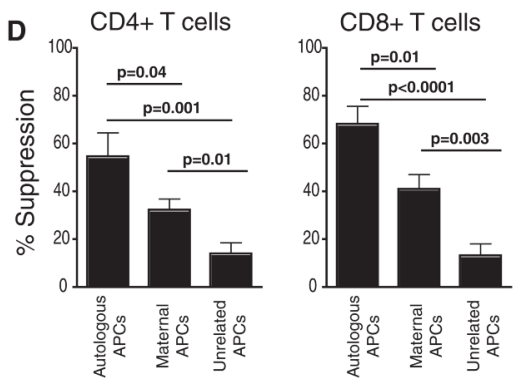

Fig. 1.

Fetal $\mathrm{T}_{\text {regs }}$ suppress fetal $\mathrm{T}$ cell responses to maternal alloantigens. (A) Fetal $\mathrm{T}$ cell proliferation after stimulation with allogeneic APCs from an unrelated donor for 5 days (3:1 ratio of fetal lymphocytes:allogeneic APCs). (B) Proliferative responses to autologous, maternal, or unrelated APCs after a 5-day MLR. Histograms depict proliferation in the presence (no depletion) or absence (CD25 depletion) of fetal $\mathrm{T}_{\text {regs }}$. CFSE, carboxy-fluorescein diacetate succinimidyl ester. (C) Summary of all experiments addressing fetal T cell proliferative responses to autologous $(n=6)$, maternal $(n=9)$, or unrelated $(n=9)$ APCs in the presence or absence of fetal $\mathrm{T}_{\text {regs. }}$. Statistical significance was determined by paired Student's $t$ test. mLN, mesenteric lymph nodes. (D) Comparison of $\mathrm{T}_{\text {regs }}$ suppression against autologous, maternal, or unrelated APCs. 
A

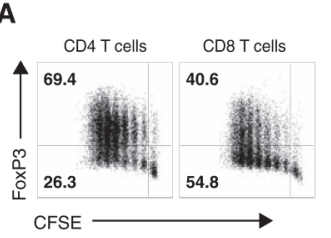

B

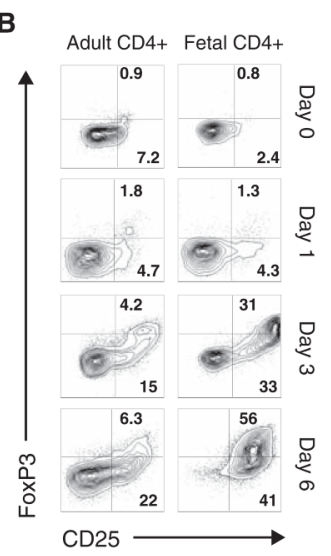

C
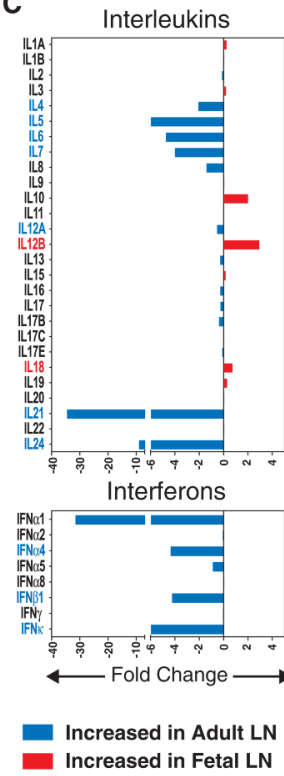

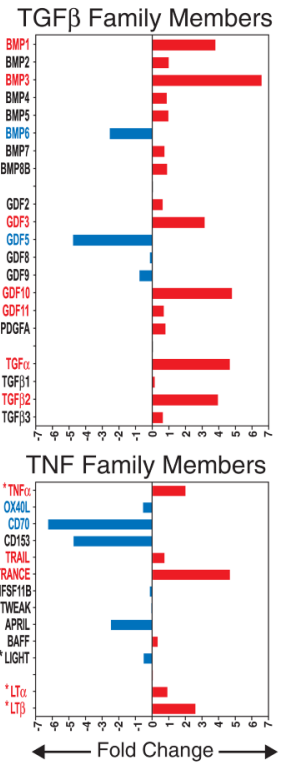

D

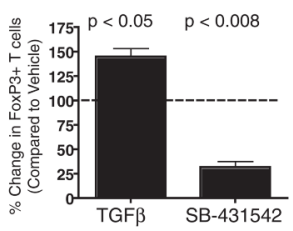

E

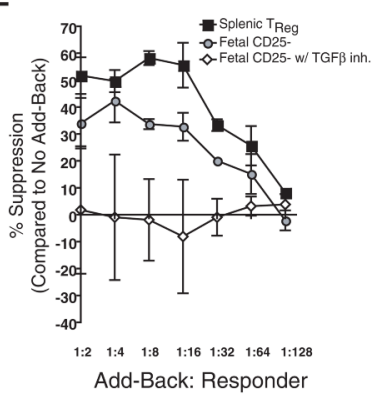

Fig. 2.

Fetal $\mathrm{T}$ cells differentiate into $\mathrm{T}_{\text {regs }}$ upon stimulation with alloantigens. (A) Fetal $\mathrm{T}$ cells depleted of CD25+FoxP3+ cells were stimulated for 5 days with unrelated APCs, and FoxP3 expression was measured in proliferating T cells. (B) Kinetic analysis of CD25 and FoxP3 upregulation by adult and fetal CD4+ T cells after stimulation with alloantigens. (C) Fold difference in cytokine mRNA expression in normal adult $(n=4)$ and fetal $(n=5)$ LNs. Genes found to be significantly different are labeled in red (fetal) or blue (adult) $(P<0.05$, unpaired Student's $t$ test). Asterisks denote TNF family members involved in organogenesis. (D) Inhibition of TGF $\beta$ signaling by addition of the activin receptor-like kinase inhibitor, SB-431542 (1 uM), which blocks FoxP3 up-regulation by fetal T cells stimulated with unrelated APCs. (E) TGF $\beta$-dependent acquisition of suppressive function after stimulation of fetal T cells with alloantigens. Error bars indicate SD observed in three separate experiments. 
A

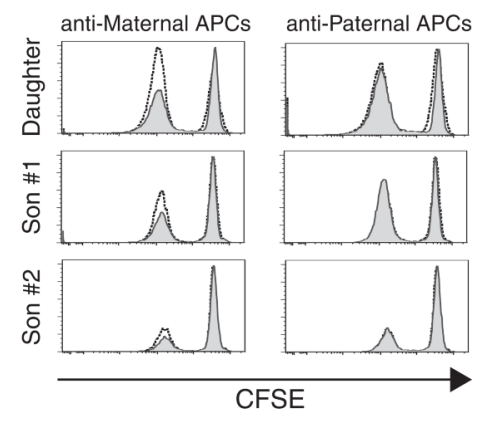

B

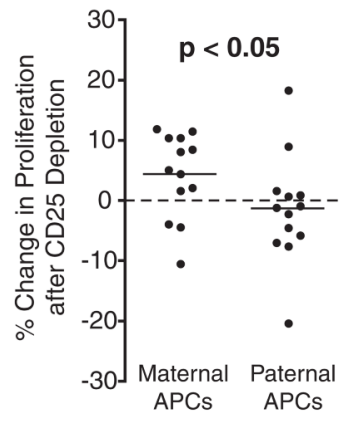

C $\begin{gathered}\text { Children } \\ \text { anti-Maternal }\end{gathered}$ Children
anti-Paternal anti-Paternal

1:3 (APCs:responders)

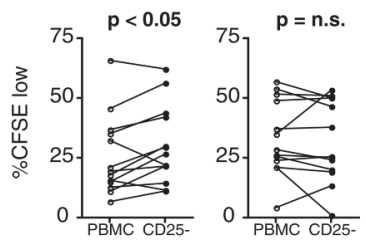

1:30 (APCs:responders)

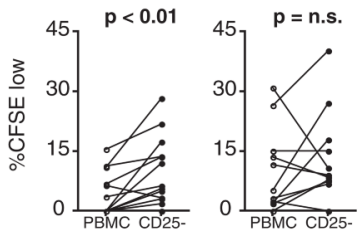

Fig. 3.

$\mathrm{T}_{\text {regs }}$ specific for non-inherited maternal alloantigens persist long after birth. (A) CD8+ T cell proliferation in mock-depleted (gray histograms) and CD25-depleted (unshaded histograms) T cells after an 8-day MLR with maternal (left) and paternal (right) APCs. Three children from a single family are represented. (B) Summary of all children tested, comparing the relative increase in proliferation after depletion of CD25+ cells from MLRs against maternal (left) or paternal (right) APCs (1:3 ratio of APCs: responders). Statistical analysis calculated by MannWhitney $U$ rank sum test. (C) Summary of individual responses of all children tested, showing proliferation of mock-depleted (PBMC) or CD25-depleted (CD25-) T cells in response to maternal or paternal APCs. Two different dilutions of APCs:responders (1:3, top; 1:30, bottom) are depicted. Statistical significance was determined by paired Student's $t$ test. 
Table 1

Maternal microchimerism in fetal LNs. We analyzed fetal mesenteric lymph nodes (18 to $22 \mathrm{~g}$. w.) for levels of maternal microchimerism with the use of two separate assays (16). Informative HLA types and/or insertion/deletion (in/del) polymorphisms are listed for each donor. "None" refers to situations where no informative HLA type or polymorphisms were identified; "Neg." refers to samples where no microchimerism was detected; N.A., not applicable.

\begin{tabular}{|c|c|c|c|}
\hline Sample number & HLA type/(in/del) marker & $\begin{array}{l}\text { \% Microchimerism } \\
\text { (HLA type) }\end{array}$ & $\%$ Microchimerism (in/del) \\
\hline 1 & DR13/SO10 & $0.3860 \%$ & $0.3080 \%$ \\
\hline 2 & None/SO3 & N.A. & $0.1640 \%$ \\
\hline 3 & DR11/None & $0.8260 \%$ & N.A. \\
\hline 4 & DR4/None & $0.0035 \%$ & N.A. \\
\hline 5 & None/None & N.A. & N.A. \\
\hline 6 & DR9/SO7B & $0.0370 \%$ & $0.0906 \%$ \\
\hline 7 & DR1/SO6 & $0.0650 \%$ & $0.0190 \%$ \\
\hline 8 & DR13/None & Neg. & N.A. \\
\hline 9 & DR7/SO8 & $0.1780 \%$ & $0.4934 \%$ \\
\hline 10 & SO6/None & $0.0062 \%$ & N.A. \\
\hline 11 & $\begin{array}{l}\text { None/SO9 } \\
\text { SO10 }\end{array}$ & N.A. & $\begin{array}{l}0.0070 \% \\
0.0039 \%\end{array}$ \\
\hline 12 & DR1/SO4B & $0.0312 \%$ & $0.0234 \%$ \\
\hline 13 & $\begin{array}{l}\text { None/SO9 } \\
\text { SO11 }\end{array}$ & N.A. & $\begin{array}{l}0.4869 \% \\
0.1933 \%\end{array}$ \\
\hline 14 & DR1/None & $0.3663 \%$ & N.A. \\
\hline 15 & DR15/SO3 & Neg. & Neg. \\
\hline 16 & DR11/None & $0.0114 \%$ & N.A. \\
\hline 17 & $\mathrm{DR} 15 / \mathrm{SO} 3$ & $0.0161 \%$ & $0.006 \%$ \\
\hline 18 & DR15/None & $0.1158 \%$ & N.A. \\
\hline
\end{tabular}

